\title{
Education and Public Outreach and Engagement at NASA's Analog Missions in 2012
}

\author{
Wendy L. Watkins ${ }^{1}$ \\ SAIC, Inc., Johnson Space Center, Houston, TX, 77058 \\ Barbara A. Janoiko ${ }^{2}$ \\ NASA, Johnson Space Center, Houston, TX, 77058 \\ Erin Mahoney ${ }^{3}$ \\ DMI, NASA Headquarters, Washington D.C., 20024 \\ and \\ Nicole B. Herrmann ${ }^{4}$ \\ ADNET Systems, Inc., NASA Headquarters, Washington D.C., 20024
}

\begin{abstract}
Analog missions are integrated, multi-disciplinary activities that test key features of future human space exploration missions in an integrated fashion to gain a deeper understanding of system-level interactions and operations early in conceptual development. These tests often are conducted in remote and extreme environments that are representative in one or more ways to that of future spaceflight destinations. They may also be conducted at NASA facilities, using advanced modeling and human-in-the-loop scenarios. As NASA develops a capability driven framework to transport crew to a variety of space environments, it will use analog missions to gather requirements and develop the technologies necessary to ensure successful exploration beyond low Earth orbit. NASA's Advanced Exploration Systems (AES) Division conducts these high-fidelity integrated tests, including the coordination and execution of a robust education and public outreach (EPO) and engagement program for each mission. Conducting these mission scenarios in unique environments not only provides an opportunity to test the EPO concepts for the particular future-mission scenario, such as the best methods for conducting events with a communication time delay, but it also provides an avenue to deliver NASA's human space exploration key messages. These analogs are extremely exciting to students and the public, and they are performed in such a way that the public can feel like part of the mission. They also provide an opportunity for crew members to obtain training in education and public outreach activities similar to what they would perform in space. The analog EPO team is responsible for the coordination and execution of the events, the overall social media component for each mission, and public affairs events such as media visits and interviews. They also create new and exciting ways to engage the public, manage and create website content, coordinate video footage for missions, and coordinate and integrate each activity into the mission timeline. In 2012, the AES Analog Missions Project performed three distinct missions - NASA Extreme Environment Mission Operations (NEEMO), which simulated a mission to an asteroid using an undersea laboratory; In-Situ Resource Utilization (ISRU) Field Test, which simulated a robotic mission to the moon searching and drilling for water; and Research and Technology Studies (RATS) integrated tests, which also simulated a mission to an asteroid. This paper will discuss the education and public engagement that occurred during these missions.
\end{abstract}

\footnotetext{
${ }^{1}$ Education and Public Outreach Lead, Advanced Exploration Systems Analog Project, YX

${ }^{2}$ Project Manager, Advanced Exploration Systems Analog Project, EA321

${ }^{3}$ Senior Communications Analyst, Strategic Analysis and Integration Division, CL

${ }^{4}$ Strategic Analyst, Strategic Analysis and Integration Division, CL
} 


\section{Introduction: Analog Missions}

$\mathrm{O}$ NE of the ways NASA tests mission concepts and technologies is by conducting analog missions on Earth. Analog missions are integrated, multi-disciplinary activities that test key features of future human space exploration missions in an integrated fashion to gain a deeper understanding of system-level interactions and operations early in conceptual development. NASA's Advanced Exploration Systems (AES) Division conducts these tests in locations that are identified based on their physical similarities to the extreme space environments of a target mission. They are conducted in remote and isolated environments to adequately represent logistical challenges associated with human spaceflight, or at NASA facilities that utilize high-fidelity, human-in-the-loop simulations. Analog missions drive innovation through collaboration of game-changing and cross-cutting technologies and mission operations scenarios. They help to define new architectures, test and validate future integrated mission concepts, and actively demonstrate rapid prototyping of advanced technologies. During these missions, NASA engineers and scientists work with representatives from other government agencies, academia and industry to gather requirements and develop the technologies necessary to ensure an efficient, effective and sustainable future for human space exploration.

\section{Importance of Analog Missions}

As NASA develops a capability-driven framework for transporting crew to a variety of space environments, it will conduct analog missions to gather requirements and develop the technologies necessary to ensure successful exploration beyond low Earth orbit. This is not only important for the future of human space exploration, but these missions also provide an opportunity to inform and engage the public in innovative ways.

\section{Importance of Education and Public Outreach During Analog Missions}

NASA's AES Analog Missions Project conducts these high-fidelity integrated tests, including the coordination and execution of a robust education and public outreach (EPO) and engagement program for each mission. Conducting these mission scenarios in unique environments not only provides an opportunity to test the EPO concepts for the particular future-mission scenario, such as the best methods for conducting events with a communication time delay, but it also provides an avenue to deliver NASA's human space exploration key messages in a very unique format.

These analogs are extremely exciting to students and the public, and they provide a tangible, exciting NASA mission performed in such a way that the public can feel like part of the operation itself. This is very beneficial in the inspiration of students in the science, technology, engineering, and mathematics (STEM). Since the tests are on Earth, sometimes near a person's hometown, the public tends to feel that the activities are more accessible to them. Analogs also provide an excellent platform for education, outreach, and engagement activities when in-space missions may sometimes seem so out-of-reach to the average person on Earth. They also provide an opportunity for crew members to obtain on-the-job training in education and public outreach activities similar to what they would perform in space.

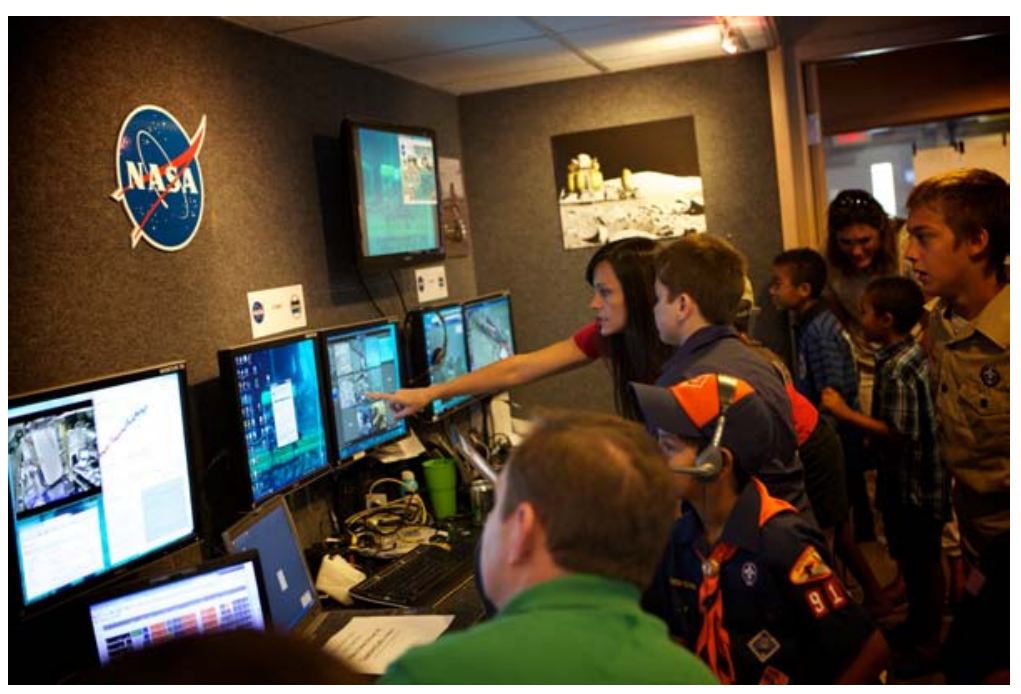

Figure 1. NEEMO 16 Outreach. Kids from a local Boy Scout troop get a personalized tour of Mobile Mission Control before partaking in a Science Under Pressure Experiment. 


\section{Analog Missions Conducted in 2012}

In 2012, the AES Analog Missions Project conducted three missions - the $16^{\text {th }}$ expedition of the NASA Extreme Environment Mission Operations (NEEMO), the 3rd International In-Situ Resource Utilization (ISRU) Analog Field Test, and The Research and Technology Studies (RATS) 2012 integrated test and simulation.

NEEMO was conducted June 11-23, with an international crew of four who spent 10 days living 62 feet (19 meters) below the surface in the National Oceanic and Atmospheric Administration's (NOAA) Aquarius Reef Base undersea research habitat, three miles off the coast of Key Largo, Florida. This year, during the $16^{\text {th }}$ expedition of NEEMO, the team returned to the bottom of the sea to simulate deep-space exploration activities of a simulated mission to an asteroid. NEEMO focused on three particular areas: communication time delays, anchoring techniques and optimal crew size.

ISRU conducted test activities on Mauna Kea, Hawaii from July 13- 21, which simulated a robotic mission to the moon searching and drilling for volatiles and consumables. The ISRU analog mission was a collaboration with NASA partners, primarily the Pacific International Space Center for Exploration Systems (PISCES) and the Canadian Space Agency (CSA). Together they performed in-situ resource utilization demonstrations, a necessary element in NASA's exploration architecture providing consumables for life support, propellants, and building materials. The tests also evaluated technologies that could be used to look for water-ice in extraterrestrial environments. Demonstrations were conducted at 9,000 and 12,000 feet and included Regolith \& Environment Science and Oxygen \& Lunar Volatile Extraction (RESOLVE) and Moon Mars Analog Mission Activities (MMAMA).

RATS 2012 marked the first time the analog mission had moved out of the desert and into indoor computerbased simulations and gravity offloading facilities. Tests were conducted from August 16-31. To simulate the microgravity environment that future explorers will experience at an asteroid, the RATS team took advantage of tools available at the Space Vehicle Mockup Facility (SVMF) at NASA's Johnson Space Center in Houston. For this mission, a crew of four used NASA's prototype multimission Space Exploration Vehicle (MMSEV), the Active Response Gravity Offload System (ARGOS), the Virtual Reality (VR) Laboratory and the Analog Mission Control

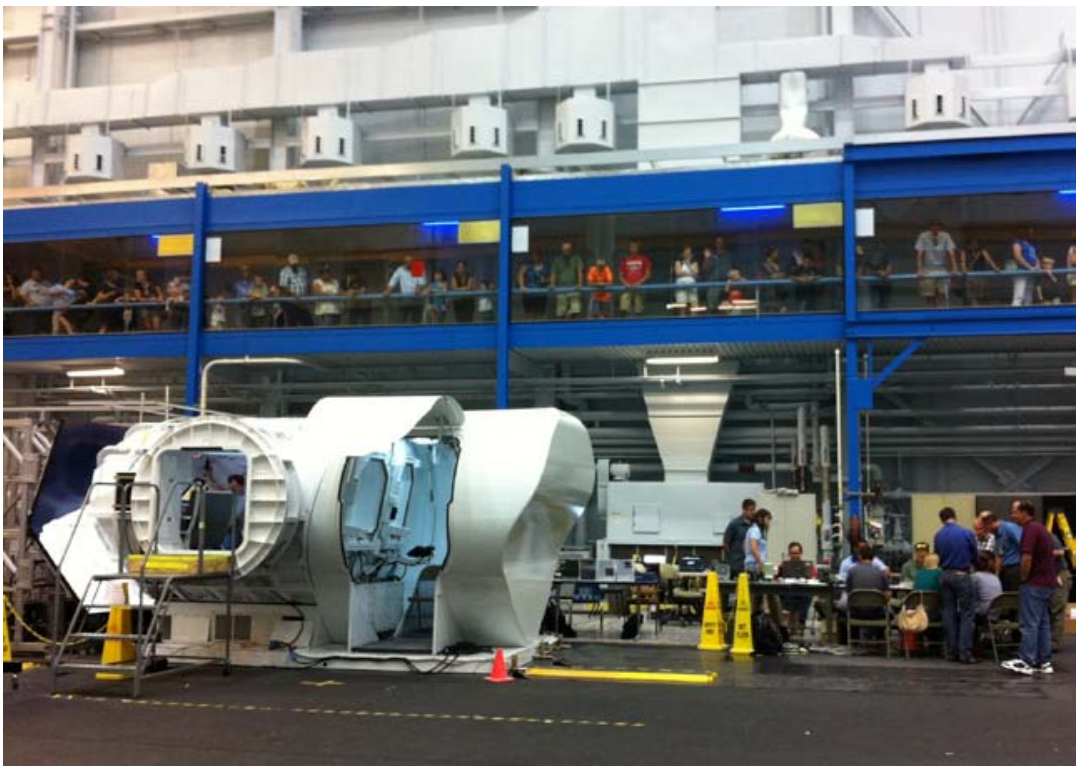

Figure 2. Tours During RATS. Hundreds, maybe thousands of individuals toured through the SVMF on the Space Center Houston Tram Tour. Handouts explaining the tests were made available to the tourists. Center (AMCC) to gather data. This data may help NASA explore an asteroid in the future. All communications and data transmissions with the AMCC were conducted over a 50-second time delay (each way), which represents the expected delay during a real mission to a Near-Earth Asteroid (NEA).

In support of NASA's strategic goal to share NASA with the public and provide opportunities for participation, the Analogs EPO team leveraged these three distinct missions to provide a wide variety of opportunities for the public, educators, and students and to to participate in real NASA activities. With all of the new tools and technologies available for world-wide connection and collaboration, the team was able to inspire thousands of individuals in one way or another throughout the missions, and in many cases, continually through social media connections.

\section{EPO Planning for Analogs}

The analog EPO team typically consists of three core EPO personnel who alternate time present in the field, one PAO person (only in the field for media, VIP, and/or community events), and photographers and/or videographers to 
support.. The core EPO team is responsible for the pre-mission planning and integration and must coordinate and collaborate with respective NASA Public Affairs Office (PAO) personnel, education points of contact, legislative affairs, and analog mission technical representatives on all EPO efforts for the mission to ensure resources are available to support their respective planned activities.

The EPO team is not only responsible for the coordination and execution of the events that occur during the missions, the overall social media component for each analog, and public affairs events such as media visits and interviews, but also all of the pre-planning and coordination that goes into making each event or activity a success. They also create new and exciting ways to engage the public, manage and create website content, coordinate video footage for missions, and coordinate and integrate each activity into the mission timeline, all with the rigor of a real space mission.

To begin the planning, the team must create and maintain a variety of social media accounts for each individual analog, which includes tools such as Facebook and Twitter for engaging

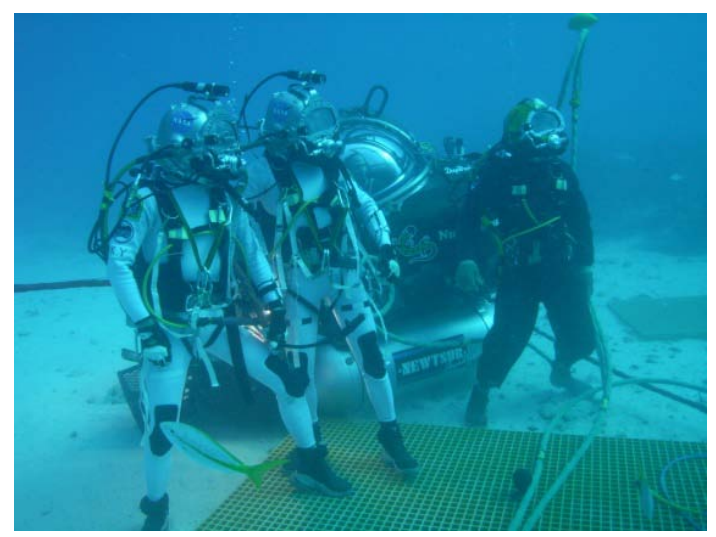

Figure 3. Beauty of Social Media. This image taken during NEEMO 16 had more than 5,900 "likes" and 936 "shares" when posted because it was shared on the agency-level social media feeds as well. interaction, conversation and questions with the audience, sharing photos and videos, crowd sourcing for ideas and participation, announcing events and activities, and potential contests. The AES Analog EPO team also maintains a YouTube channel for videos, a Flickr account for official mission photos, and an Ustream channel for all livestreamed events, activities, and mission camera feeds. Most of the analog missions have an established following in the social media arena, but the audience continues to grow tremendously, especially during peak mission times. Dedicated web pages are created on the NASA.gov website at http://www.nasa.gov/exploration/analogs/index.html for each analog mission as well. Typically, the website from the previous mission is updated with the current mission, and the past data is archived.

Months before the actual mission, the team initiates a call for interested groups, events, and connection activities, usually utilizing the established education office soliciatation methods. The typical groups interested in connecting with analog crews, teams, and subject matter experts for live events include schools, museums, specialty organizations, and the general public. The general public connections usually occur through venues such as the Explorations Space Theater at the Kennedy Space Center Visitor Complex or Space Center Houston. School and classroom connections and events are typically coordinated through the education office and the Digital Learning Network (DLN) group. DLN events last for an hour, and contain basic space education programming along with the special connection with the analog team for an exciting on-location learning experience. Once dates and times are set for the mission, all negotiations for event times begin. Just as available crew-time on the International Space

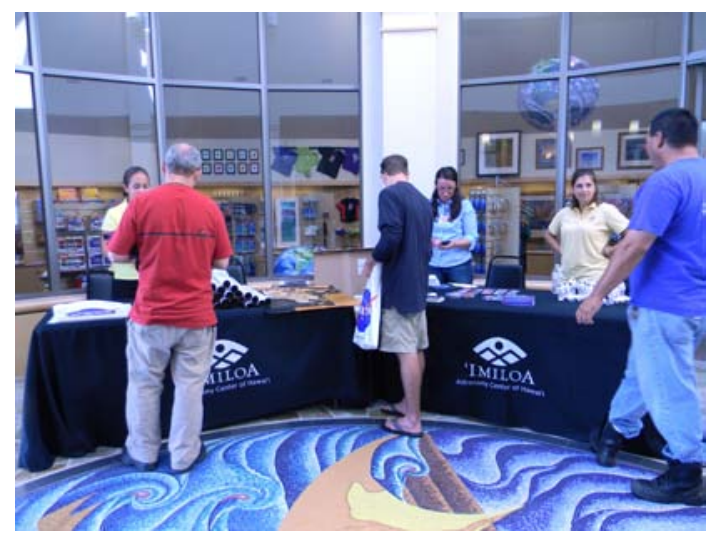

Figure 4. Imiloa Astronomy Center Outreach Event for ISRU. Over 475 individuals visited the Imiloa Astronomy Center to learn about the ISRU Field Test and drive rovers in the parking lot of the center.
Station (ISS) is limited, available crew-time during these tests is limited as well. Once the activities are all agreed upon, the EPO team works with the mission timeline planners to integrate the events and activities into the mission timeline. The EPO team must then work with the communications group to ensure that all of the connection hardware, software, and bandwidth for connections will be available at the test site for each event and connection.

Within the planning phase, all print materials are developed and designed, including posters, baseball cards, fact sheets, and brochures. Fact sheet content is coordinated through PAO, as well as planning for press and media releases. Days and times are set aside for potential onsite media events during the mission as well. These media events require integration into the mission timeline, but also require the in-person attendance of official PAO personnel onsite when media are present. Integration and coordination are key to the success of the EPO plan for analog missions. After events and activities are coordinated and 
confirmed, the EPO team develops an official EPO schedule and plan for the analog to distribute to all interested parties.

During the mission, the EPO team is required to see every scheduled event through from setup to completion, and often appear as an on-camera host for events. Since there are so many simultaneous activities and events, the EPO team must create a resource-load matrix to show who is responsible for each task. Among the media connections coordinated through PAO, a live, on-location ISS Update is also sometimes performed. This is a daily show that is broadcast live on NASA TV. The PAO officer typically interviews a crew member or team member for 15 minutes during the hour-long segment. The show is recorded while being

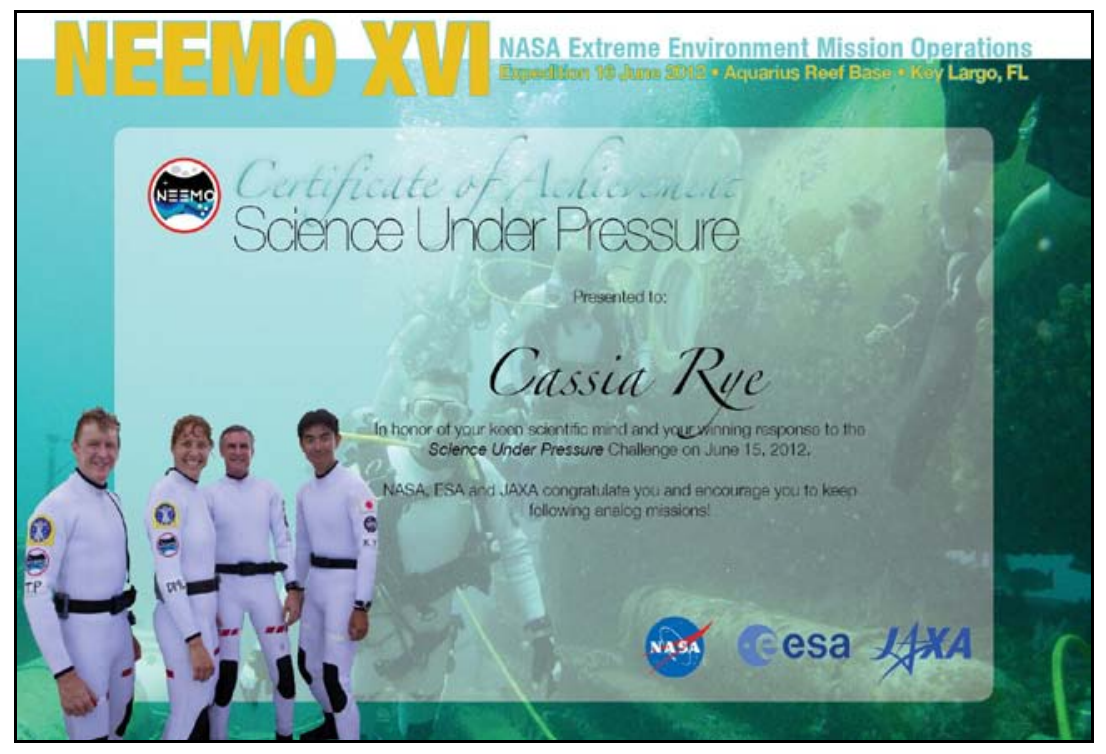

Figure 5. Science Under Pressure. Example of digital certificate given to correct responders during Science Under Pressure social media public engagement activities.

broadcast, and uploaded to the NASA.gov website. While the live events and connections occur intermittently throughout the mission, there are also simultaneous and ongoing activities that require full-time attention, such as maintaining all social media activity, coordinating blogs from the crew and team, coordinating video footage and photos, selecting the "best of" photos and uploading to Flickr, managing all onsite visitors (both scheduled and unscheduled), and overseeing or making all website updates.

Along with these tasks, the EPO team participates in a portion of the simulation to test hypothesis on the best methods for outreach events during the specified mission being tested. This includes tests with communication

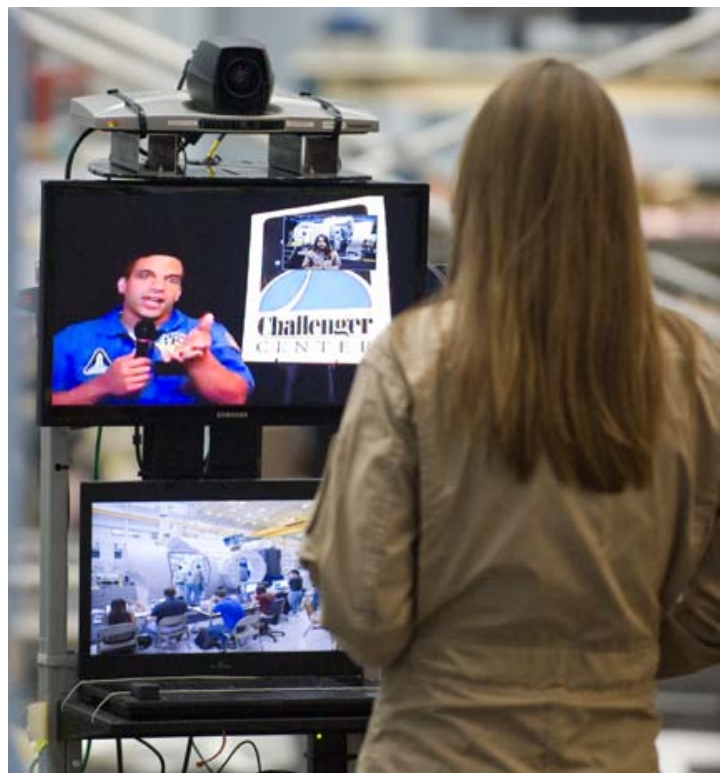

Figure 6. Outreach with Challenger Learning Center. RATS crewmember performs a live, webstreamed, outreach event through the DLN at Johnson Space Center. The Challenger Learning Center connects with analogs whenever possible. delays, as done during the NEEMO mission. The EPO team conducted two scenarios for the tests to show which would be more feasible during a mission with a long communications delay. Scenario 1: EPO posed questions that reached the aquanaut crew 50 seconds later. The aquanauts then formulated their response and transmitted it, reaching the PAO team 50 seconds later. The experience was slow and frustrating. Scenario 2: EPO sent questions to the aquanaut crew in advance. When the simulation began, the aquanaut crew read all of the questions and answered them in one audio transmission. Following that audio transmission, PAO posed one final unrehearsed question, which was subjected to the 50second transmission delay each way. The tests concluded that it would be more palatable to the public to view the second scenario. Scenario one proved to be painful to watch. Example videos of these tests are posted on the analogs YouTube channel.

During analogs where there is limited availability of crew and team members for education and outreach events to the public, the EPO team has coordinated with other agencies to create innovative ways to engage the public through other methods. For example, during the NEEMO 16 mission, the EPO team collaborated with the European Space Agency (ESA), the Japan Aerospace Exploration Agency (JAXA), the NASA Teaching from Space (TFS) group, and other agencies, to conduct a fun, engaging activity involving topside team 
members and crew in the habitat. For one week during the mission, the crew conducted experiments proposed by educators and scientists from NASA, ESA and JAXA. These experiments demonstrated how science experiments yielded different results at different atmospheric pressures. The topside team performed an experiment and posed the questions to the public of what they thought would happen when the crew conducted the experiment in the Aquarius Habitat that maintains an atmospheric pressure that is about 2.5 times that of pressure at the surface. The activity was aptly named, "Science Under Pressure," and gained quite a following. NEEMO social media fans were invited to predict the outcome of each experiment, and correct responses received a digital certificate to display on their own social media page, or print as a keepsake. Videos from the Science Under Pressure activity received over 22,078 views during the two week NEEMO mission. Example videos are on the analog YouTube channel at http://youtu.be/m-8O2iJmDuM for the topside version of the remote controlled helicopter, and at http://youtu.be/GFbDCYQHWYA for the video of the experiment in the Aquarius Habitat.

The EPO Team coordinated and performed the following events during the missions in 2012:

\begin{tabular}{|l|l|}
\hline Live Events During Analogs & \\
\hline \multirow{2}{*}{ NEEMO } & $\begin{array}{l}\text { Conducted } 17 \text { live EPO events, broadcast on Ustream reaching } \\
2,960+\text { interactive audience members }\end{array}$ \\
\cline { 2 - 2 } & $\begin{array}{l}\text { Conducted } 6 \text { ISS Update Interviews for NASA TV with 7,433+ } \\
\text { views during event }\end{array}$ \\
\hline \multirow{2}{*}{ RARU } & $\begin{array}{l}\text { Conducted 4 live EPO events back to the mainland with 1423+ } \\
\text { views on Ustream and 275+ interactive audience members }\end{array}$ \\
\cline { 2 - 2 } & Visited various local schools \\
\cline { 2 - 2 } & $\begin{array}{l}\text { Conducted a robust community event at Imiloa Astronomy Center } \\
\text { in Hilo, HI with over 475+ visitors }\end{array}$ \\
\hline & $\begin{array}{l}\text { Conducted 7 live EPO events with a combined audience of 3,528+ } \\
\text { audience members (459+ in attendance, 3,069+ virtual) }\end{array}$ \\
\cline { 2 - 2 } & $\begin{array}{l}\text { Hosted 7 media outlets in person for interviewing and filming, 3 } \\
\text { city council members, 50+ onsite VIPs, 136+ onsite visitors in } \\
\text { various tours, and hundreds of Space Center Houston tourists }\end{array}$ \\
\hline
\end{tabular}

Other exciting outreach events have included onsite visits from the public during NEEMO and ISRU, and hosting hundreds of visitors onsite for tours during RATS, including spectators touring through the SVMF on the Space Center Houston Tram Tour, as well as Space Flight Awareness (SFA) Honorees, Media, Congressional

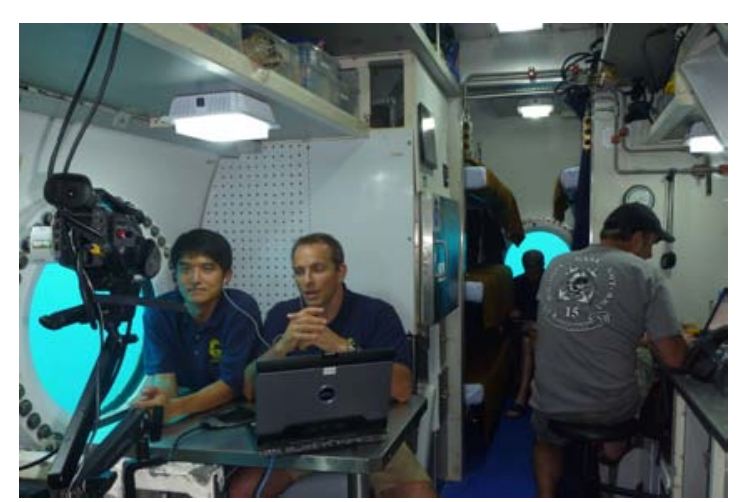

Figure 7. Outreach from Aquarius. Each analog presents a different set of connection challenges for EPO but the Aquarius Habitat used for NEEMO has a built-in infrastructure. Crewmembers connect with a classroom from 50 feet below the surface. visitors, and even the entertainer Yanni, who all received printed literature on the tests. During ISRU, the team worked with a local astronomy for a dynamic community event with over 475 visitors who were invited to operate remote controlled rovers, and interact with team members for live demonstrations of hardware and software used during the mission. Occasionally during the missions, EPO team members would conduct on-thefly connections with classrooms using an informal format with in iPad and Skype.

Special event opportunities were always a welcome possibility, such as the infamous video call from the NASA Administrator, Charles Bolden, to two crew members of NEEMO 16: NASA Astronaut Dorothy "Dottie" MetcalfLindenburger, and ESA Astronaut Timothy Peake, who were fully suited and in the water for a simulated Extravehicular Activity (EVA). The video of the live call is located on the analog YouTube channel. The live video had over 1,969 viewers while on the air. 


\section{EPO Post-Mission Activities}

The EPO team is responsible for all post-mission metric gathering and lessons learned documentation related to the education and public outreach. The summary metrics for the NEEMO, ISRU, and RATS during 2012 were very impressive and show that analogs do not go unnoticed by the general public. In fact, there are many individuals who inquire regularly about the missions, and some school science clubs and groups who base activities around analog operations.

\begin{tabular}{|l|l|}
\hline METRICS for 2012 ANALOGS & \\
\hline Live Audience Members (not including virtual viewers) & $7,638+$ \\
\hline In-Person Tours and Event Attendees (not including Space Center Houston Tram Tours) & $776+$ \\
\hline Webpage Views During Missions & $94,359+$ \\
\hline Analog Website Blog Views During Missions & $21,603+$ \\
\hline Fact Sheets Download from Website During Missions & $1,000+$ \\
\hline Photos Posted to Flickr During Missions & $1,763+$ \\
\hline Views During Missions of Images Posted on Flickr & $30,716+$ \\
\hline Views During Missions of Videos Posted on Analog YouTube Channel & $40,519+$ \\
\hline New Followers to Official Twitter Accounts (NEEMO, RATS, and ISRU) & $19,500+$ \\
\hline New Followers to Official Facebook Accounts (NEEMO, RATS, and ISRU) & $20,000+$ \\
\hline
\end{tabular}

\section{Appendix Acronym List}

$\begin{array}{ll}\text { AES } & \text { Advanced Exploration Systems Division (or Project) (HEOMD) } \\ \text { AMCC } & \text { Analog Mission Control Center } \\ \text { ARGOS } & \text { Active Response Gravity Offload System } \\ \text { CSA } & \text { Canadian Space Agency } \\ \text { DLN } & \text { Digital Learning Network } \\ \text { EPO } & \text { Education and Public Outreach } \\ \text { ESA } & \text { European Space Agency } \\ \text { EVA } & \text { Extravehicular Activity } \\ \text { ISRU } & \text { In-Situ Resource Utilization } \\ \text { ISS } & \text { International Space Station } \\ \text { JAXA } & \text { Japanese Aerospace Exploration Agency } \\ \text { JSC } & \text { Johnson Space Center (NASA) } \\ \text { MMAMA } & \text { Moon Mars Analog Mission Activity } \\ \text { MMCC } & \text { Mobile Mission Control Center } \\ \text { MMSEV } & \text { Multi-Mission Space Exploration Vehicle } \\ \text { NASA } & \text { National Aeronautics and Space Administration } \\ \text { NEA } & \text { Near Earth Asteroid } \\ \text { NEEMO } & \text { NASA Extreme Environment Mission Operations } \\ \text { NOAA } & \text { National Oceanic and Atmospheric Administration } \\ \text { PAO } & \text { Public Affairs Office } \\ \text { PISCES } & \text { Pacific International Space Center for Exploration Systems } \\ \text { RATS } & \text { Research and Technology Studies } \\ \text { RCS } & \text { Reaction Control System } \\ \text { RESOLVE } & \text { Regolith and Environment Science and Oxygen and Lunar Volatile Extraction } \\ \text { SFA } & \text { Space Flight Awareness } \\ \text { STEM } & \text { Science, Technology, Engineering, and Mathematics } \\ \text { SVMF } & \text { Space Vehicle Mockup Facility } \\ \text { TFS } & \text { Teaching from Space } \\ \text { VAPoR } & \text { Volatile Analysis by Pryolysis of Regolith } \\ \text { VR } & \text { Virtual Reality } \\ & \end{array}$

